three judgments Commission v. Portugal (golden share), 2002; Commission v. France (golden share), 2002; and Commission v. Belgium (golden share), 2002 began is excluded, as is the thread that began with Bordessa, 1995. The likes of Defrenne II, 1976 and Mangold, 2005 are not included, either. However, the series beginning, respectively, with Demirel, 1987; Kziber, 1991; Krid, 1995; Kondova, 2001; Simutenkov, 2005; and Stamm, 2008 are all included.

\title{
II The structure of the book
}

The first part of the book, 'the case-law', is devoted to a thick description of the case-law within the framework noted above. Each chapter in this first part encompasses a decade of case-law. Each decade is further broken down into 'workers' - or 'workers and citizens' - 'establishment' including diplomas, 'social security', and 'services'. The description within each section sometimes follows a chronological sometimes a content-based order, depending on various factors. The few decisions of the early days are grouped according to substance. Their implications for other decisions are rather evident. Later on, as the case-law developed, decisions became typically more complex and addressed various points while having multiple cross-implications. So a chronological description is more suitable for this time period. Within social security, decisions are easily categorized according to topics - namely aggregation, family benefits, unemployment benefits, etc. - owing to the rather homogenous and self-referential nature of social security. Within the freedom of services judgments are generally more heterogeneous. Services cover a vast array of topics and have multiple links to establishment. Hence, a chronological order combined with categorization according to substance is applied for services. Overall, this structure should make it easy for practitioners to navigate the case-law and to tap into the context of decisions they previously identified as interesting. In general, the presentation in the part on 'the case-law' is as neutral as possible. Opinionated qualification, e. g. through the use of adjectives, is avoided as is analysis more generally.

The second part, 'the evolution of interpretive formulas', takes the body of case-law identified in the first part and traces how certain interpretive formulas evolve. Some interpretive formulas are thus mapped out through the entire caselaw of persons and services, from the beginning to the present. It is examined where certain formulas originate, when they appear, and how they influence the Court's decisions. More succinctly, the questions are answered where the formulas are from, when they are used, and how powerful they are. The power of a formula is examined and qualitatively assessed in each decision where it occurs. 'Power' in this context is represented by the 'spin' a formula exerts within a decision. This 'spin' is gradual. In casual parliance, 'spin' occurs when one reads a judgment, arrives at an interpretive formula which raises a certain expectation of 
the way the decision will go - and the decision then indeed goes this expected way and ends there.

Three sets of interpretive 'formulas' are examined. First, in the chapter entitled 'broad', formulas are examined that embody either broad or restrictive interpretation. Which formulas exist in the body of case-law examined that embody a broad or restrictive approach? In which circumstances are they typically used? How do they evolve? When are they decisive for the Court's decision, when do they provide impetus, exert 'spin'? These are the questions that are answered first for 'broad' interpretation. The chapter on 'broad' interpretive formulas is different from the other two chapters on interpretive formulas in that it may contain aspects that are relevant beyond the law of the Union and the Court of Justice. Broad or restrictive interpretation is common in other legal orders, too, like in international and domestic law. Yet, these broader implications and possible cross-connections are not addressed in this book, because it is about the case-law of the Court of Justice. In the next chapter the above questions are pondered for interpretive formulas in which the Court relied on the idea that parts of Union law merely coordinated national law, as an alternative to harmonizing it. This is the chapter entitled 'coordinated'. This interpretation is highly specific for the law of the Union and the case-law of the Court. Coordination of legal systems is - at least in this terminology and as far as can be judged - unique to the law of the Union. Within this law, social security is of primary importance. The final chapter labelled 'fundamental' ponders the above questions for formulas drawing on the idea that some notions are fundamental, while others are not. Like broad interpretation, interpretation relying on hierarchy, such as a notion being fundamental, is not unique to the law of the Union. Most legal orders, perhaps even all, at one point or another prioritize some notions over others. However, this chapter is uniquely tied to the law of the Union in that it primarily deals with Union citizenship and an intepretive formula used exclusively with regard to it ('the fundamental status').

\section{Why is the first part on 'the case-law' necessary? Why not cover more interpretive formulas?}

Why not drop the voluminous first part on 'the case-law' and cover more interpretive formulas? And why are three interpretive formulas investigated and others left aside? Answers to these questions are not easy to give. They to some degree concern scientific honesty and, in addition, require a deep understanding of the case-law that is the subject of the first part of this book. Admittedly, the evolution of further interpretive formulas could be traced. For instance, the formula used to argue that social security rights based solely on national law must not be lost after the right of free movement has been exercised would have been an alternative; or the formula relying on the need for cohesion of the tax system. 